\title{
A selective medium for the enumeration and differentiation of Lactobacillus delbrueckii ssp. bulgaricus
}

\author{
Nwadiuto O. Nwamaioha and Salam A. Ibrahim ${ }^{1}$ \\ Food Microbiology and Biotechnology Laboratory, Food and Nutritional Sciences Program, \\ North Carolina Agricultural and Technical State University, Greensboro 27411
}

\begin{abstract}
Modified reinforced clostridial medium (mRCM) was developed and evaluated for the differential enumeration of Lactobacillus delbrueckii ssp. bulgaricus. Lactobacillus bulgaricus, an important species of lactic acid bacteria with health benefits, is used in the production of yogurt and other fermented foods. Our results showed that supplementing reinforced clostridial medium with $0.025 \% \mathrm{CaCl}_{2}, 0.01 \%$ uracil, and $0.2 \%$ Tween 80 (mRCM) significantly enhanced the growth rate of L. bulgaricus RR and ATCC 11842 strains as measured by the optical densities of these strains after $12 \mathrm{~h}$ of incubation at $42^{\circ} \mathrm{C}$. The bacterial populations (plate count) of the RR and ATCC 11842 strains were 0.76 and $0.77 \mathrm{log} \mathrm{cfu} / \mathrm{g}$ higher in mRCM than in de Man, Rogosa, and Sharpe and reinforced clostridial medium media, respectively. Conversely, the population counts for other bacterial species (Bifidobacterium, Lactobacillus rhamnosus, and Lactobacillus reuteri) were significantly inhibited in the mRCM medium. The addition of aniline blue dye to mRCM (mRCM-blue) improved the selectivity of L. bulgaricus in mixed lactic bacterial cultures compared with de Man, Rogosa, and Sharpe medium and lactic agar with regard to colony appearance and morphology. The mRCM-blue performed better than the conventional medium in culturing, enumerating, and differentiating L. bulgaricus. Therefore, mRCM-blue could be used as a selective medium to enhance the growth and differentiation of L. bulgaricus in order to meet the increasing demand for this beneficial species of bacteria.
\end{abstract}

Key words: Lactobacillus bulgaricus, selective medium, mixed culture, lactic acid bacteria, fermented food

Received November 19, 2017.

Accepted February 12, 2018.

${ }^{1}$ Corresponding author: ibrah001@ncat.edu

\section{INTRODUCTION}

The idea that viable microorganisms could be used to prevent and treat diseases first became prominent in the early 20th century. Elie Metchnikoff postulated that replacing the putrefactive bacteria in the gut with lactic acid bacteria (LAB) could restore bowel health and, as a result, prolong the life of the host (Anukam and Reid, 2007). Metchnikoff believed that the beneficial effect of drinking Bulgarian milk was a result of the implantation and colonization of a particular LAB in the gut (Kulp and Rettger, 1924). His hypothesis seemed validated by the fact that poor peasant Bulgarian farmers who consumed fermented goat milk lived healthier and longer lives. The bacteria that Metchnikoff was referring to in his famous work was the "Bulgarian Bacillus," which later became known as Lactobacillus delbrueckii ssp. bulgaricus (Michaylova et al., 2007). Lactobacillus bulgaricus has been widely used for decades in the production of fermented products, especially yogurt and some cheeses. Yogurt is defined as coagulated milk, fermented by L. bulgaricus and Streptococcus thermophilus. Several studies have linked the consumption of yogurt bacteria to a reduced risk of colorectal cancer, the common cold, and inflammatory bowel disease (Wollowski et al., 1999; Borruel et al., 2002; Makino et al., 2010). Due to the high level of yogurt consumption in the United States (Nielsen and Ogden, 2015), there is a need to isolate new strains of $L$. bulgaricus in order to meet increased yogurt production demands. Although different media have been proposed to selectively enumerate specific LAB (Shah, 2000; Van de Casteele et al., 2006; Tabasco et al., 2007; Galat et al., 2016), these media do not selectively enhance the growth of L. bulgaricus in the presence of other LAB. Thus, the aims of this study were (1) to develop and evaluate a modified medium for the selective enumeration and differentiation of L. bulgaricus and (2) to validate the effectiveness of the modified medium in isolating $L$. bulgaricus from mixed LAB cultures and to compare the results with those of standard media - de Man, Rogosa, and Sharpe medium (MRS) and lactic $\operatorname{agar}(\mathbf{L A})$. 


\section{MATERIALS AND METHODS}

\section{Bacterial Species}

Two strains of $L$. bulgaricus and 3 species of probiotic bacteria were selected for the present study. The $L$. bulgaricus RR strain was supplied by Robert F. Roberts (Department of Food Science, Pennsylvania State University, State College). Lactobacillus delbrueckii ssp. bulgaricus ATCC 11842 was purchased from the American Type Culture Collection (Manassas, VA). Lactobacillus rhamnosus ATCC 53103, Lactobacillus reuteri 20016, and Bifidobacterium bifidum ATCC 15696 were obtained from the Food Microbiology Laboratory at North Carolina Agriculture and Technical State University (Greensboro). All bacterial species were maintained in a glycerol stock solution at $-80^{\circ} \mathrm{C}$ until further use.

\section{Inoculum Preparation}

A total of $0.1 \mathrm{~mL}$ of stock culture containing L. bulgaricus RR, L. bulgaricus ATCC 11842, L. rhamnosus ATCC 53103, L. reuteri, and Bifidobacterium was cultured anaerobically overnight in $7 \mathrm{~mL}$ of MRS broth (Neogen Co., Lansing, MI) at $42^{\circ} \mathrm{C}$. Each culture was streaked onto MRS agar, incubated at $42^{\circ} \mathrm{C}$ for $48 \mathrm{~h}$, and then stored at $4^{\circ} \mathrm{C}$. To prepare a working culture solution, a single colony of each bacterial species was activated in $7 \mathrm{~mL}$ of MRS broth and incubated at $42^{\circ} \mathrm{C}$ for 16 to $18 \mathrm{~h}$. Activated cultures were then washed twice with $1 \times$ sterilized PBS $(\mathrm{pH} 7.4)$ at 10,000 rpm for $10 \mathrm{~min}$ at $4^{\circ} \mathrm{C}$.

\section{Medium Preparation}

Lactobacilli MRS Medium. Lactobacilli MRS broth was prepared by dissolving $55 \mathrm{~g}$ of MRS (Neogen Co.) and $0.5 \mathrm{~g}$ of $\mathrm{L}$-cysteine in $1 \mathrm{~L}$ of deionized distilled water. The broth was stirred until all particles were completely dissolved. One liter of MRS agar was prepared the same way as the broth but with $15 \mathrm{~g}$ of added agar powder. The MRS medium was then sterilized at $121^{\circ} \mathrm{C}$ for $15 \mathrm{~min}$.

Reinforced Clostridial Medium. Reinforced clostridial medium (RCM) broth (Neogen Co.) was prepared by dissolving $38 \mathrm{~g}$ of RCM in $1 \mathrm{~L}$ of deionized distilled water. Fifteen grams of agar was added to 1 $\mathrm{L}$ of freshly prepared RCM broth to make RCM agar. The medium was heated while undergoing constant stirring until all particles were dissolved. Both agar and broth were sterilized at $121^{\circ} \mathrm{C}$ for 15 min and stored at $4^{\circ} \mathrm{C}$ until needed.
Modified RCM. Modified RCM (mRCM) was prepared by dissolving $10 \mathrm{~g}$ of peptone no. $3,10 \mathrm{~g}$ of beef extract, $5 \mathrm{~g}$ of yeast extract, $10 \mathrm{~g}$ of lactose, $5 \mathrm{~g}$ of sodium chloride, $3 \mathrm{~g}$ of sodium acetate, $2 \mathrm{~g}$ of $\mathrm{K}_{2} \mathrm{HPO}_{4}$, $0.1 \mathrm{~g}$ of uracil, $0.25 \mathrm{~g}$ of calcium chloride, $0.2 \%$ Tween 80 , and $0.5 \mathrm{~g}$ of L-cysteine in $1 \mathrm{~L}$ of deionized distilled water. The mRCM broth was adjusted to a final $\mathrm{pH}$ of $6.0 \pm 0.2$. Differential batches of $\mathrm{mRCM}$ agar were prepared by dissolving $0.01 \%$ aniline blue, $0.004 \%$ bromocresol green, and $0.004 \%$ bromophenol blue dyes and $0.075 \mathrm{~g} / \mathrm{L}$ of X-gal into individual $250-\mathrm{mL} \mathrm{mRCM}$ broths. Four grams of agar was added to $250-\mathrm{mL}$ broths and autoclaved at $121^{\circ} \mathrm{C}$ for $15 \mathrm{~min}$.

$\boldsymbol{L} \boldsymbol{A}$. The LA was prepared according to Matalon and Sandine (1986) with slight modification. Five grams of lactose, $7.5 \mathrm{~g}$ of dextrose, $2.5 \mathrm{~g}$ of fructose, $20 \mathrm{~g}$ of casein enzymatic hydrolysate, $5.0 \mathrm{~g}$ of yeast extract, $0.5 \mathrm{~g}$ of ascorbic acid, $1.5 \mathrm{~g}$ of sodium acetate, $4 \mathrm{~g}$ of sodium chloride, $2.5 \mathrm{~g}$ of gelatin, and $15 \mathrm{~g}$ of agar were dissolved in $1 \mathrm{~L}$ of deionized water. The medium was mildly heated with constant agitation, allowed to completely dissolve over $30 \mathrm{~min}$, and then sterilized at $121^{\circ} \mathrm{C}$ for $15 \mathrm{~min}$.

\section{Inoculation Procedure and Bacterial Enumeration}

Lactobacillus bulgaricus RR and ATCC 11842 cultures were serially diluted in PBS. Batches of MRS, RCM, and differential mRCM broths were inoculated with $0.1 \mathrm{~mL}$ of a bacterial dilution, corresponding to approximately $3.3 \log \mathrm{cfu} / \mathrm{mL}$, and then thoroughly mixed. Each batch was incubated at $42^{\circ} \mathrm{C}$ for $12 \mathrm{~h}$, and growth was monitored using an Evolution 201 UV-visible spectrophotometer (Thermo Scientific, Waltham, $\mathrm{MA})$ at $610 \mathrm{~nm}$. At the end of the incubation period, 1 $\mathrm{mL}$ of each sample was withdrawn and serially diluted in PBS. Volumes $(0.1 \mathrm{~mL})$ of each appropriate dilution were then surface plated onto duplicate agar of MRS, $\mathrm{RCM}$, and differential $\mathrm{mRCM}$ and incubated at $42^{\circ} \mathrm{C}$ for $72 \mathrm{~h}$. The inoculation procedure and enumeration of L. rhamnosus, L. reuteri, and Bifidobacterium were conducted as described above, but only in MRS and a differential mRCM medium. Colonies on the differential media were observed for clarity, distinction, and size, and digital photographs were taken.

\section{Enumeration of L. bulgaricus in Commercial Yogurts}

Standard LAB culture was prepared by mixing $1 \mathrm{~mL}$ of pure strains of L. bulgaricus (RR and ATCC 11842), L. reuteri 20016, L. rhamnosus and Bifidobacterium in a test tube. One milliliter of the mixed LAB culture was serially diluted in PBS and plated on $\mathrm{mRCM}$ aniline 
Table 1. Composition of commercial yogurt used in the study

\begin{tabular}{lll}
\hline Product code & Origin & Lactic acid bacteria and bifidobacteria composition as labeled \\
\hline NSY & Middle East & S. thermophilus, L. bulgaricus \\
AYG & Middle East & S. thermophilus, L. bulgaricus \\
HYG & Middle East & S. thermophilus, L. bulgaricus \\
GVO & United States (CA) & Live and active cultures \\
OPO & United States & S. thermophilus, L. bulgaricus, L. acidophilus, bifidus, L. casei \\
SFO & United States (NH) & S. thermophilus, L. bulgaricus, L. acidophilus, L. rhamnosus, L. paracasei, bifidus \\
DND & United States (NY) & L. bulgaricus, S. thermophilus, bifidus, L. acidophilus, L. casei \\
\hline
\end{tabular}

${ }^{1}$ S. $=$ Streptococcus; L. = Lactobacillus.

blue and MRS. The plates were incubated at $40^{\circ} \mathrm{C}$ for $72 \mathrm{~h}$. Colonies of L. bulgaricus on both media were used as standards to identify the bacteria in the commercial yogurt samples.

Seven commercial yogurts were used for this study (Table 1). Four of the yogurt products were obtained from local grocery stores in Greensboro, North Carolina, and 3 products were imported from the Middle East. Ten milliliters of each yogurt was mixed with 90 $\mathrm{mL}$ of $15 \%$ instant dry milk powder and incubated for 4 h. One milliliter of each freshly prepared yogurt culture was serially diluted in $9 \mathrm{~mL}$ of PBS solution. Aliquots $(0.1 \mathrm{~mL})$ of the appropriately diluted sample were inoculated into each medium (mRCM aniline blue, MRS, and LA) and incubated at $40^{\circ} \mathrm{C}$ for $72 \mathrm{~h}$. Colonies of L. bulgaricus on each medium were then counted and compared against a standard mixed LAB culture.

\section{Statistical Analyses}

Data were analyzed using SAS version 9.4 (SAS Institute Inc., Cary, NC) for statistical analysis, and 1-way ANOVA was used to determine significant differences between values. Significant differences $(P<0.5)$ between means of absorbance values (optical density; OD) and bacterial populations (colony-forming units) were compared using Tukey's test. All bacterial population counts were subjected to $\log _{10}$ transformation before analysis.

Table 2. Growth (mean $\pm \mathrm{SD} ; \mathrm{n}=3$; optical density at $610 \mathrm{~nm}$ ) of Lactobacillus bulgaricus ATCC 11842 in different media after $12 \mathrm{~h}$ of incubation at $42^{\circ} \mathrm{C}$

\begin{tabular}{lccc}
\hline & \multicolumn{3}{c}{ Time $(\mathrm{h})$} \\
\cline { 2 - 4 } Medium $^{1}$ & 0 & 6 & 12 \\
\hline MRS & $0.001 \pm 0.00^{\mathrm{a}}$ & $0.054 \pm 0.01^{\mathrm{a}}$ & $0.71 \pm 0.13^{\mathrm{b}}$ \\
RCM & $0.002 \pm 0.00^{\mathrm{a}}$ & $0.049 \pm 0.01^{\mathrm{a}}$ & $0.66 \pm 0.09^{\mathrm{b}}$ \\
mRCM & $0.001 \pm 0.00^{\mathrm{a}}$ & $0.050 \pm 0.02^{\mathrm{a}}$ & $1.24 \pm 0.17^{\mathrm{a}}$ \\
\hline
\end{tabular}

${ }^{\mathrm{a}, \mathrm{b}}$ Means with different superscripts within a column differ significantly $(P<0.05)$.

${ }^{1} \mathrm{MRS}=$ de Man, Rogosa, and Sharpe medium; RCM = reinforced clostridial medium; $\mathrm{mRCM}=$ modified reinforced clostridial medium .

\section{RESULTS}

Preliminary testing showed that supplementing MRS with individual treatments of $0.025 \% \mathrm{CaCl}_{2}, 0.01 \%$ uracil, and $0.2 \%$ Tween 80 enhanced the colony size and visibility of $L$. bulgaricus RR compared with other treatments $\left(0.02 \% \mathrm{ZnSO}_{4}, 0.01 \%\right.$ arginine, $2 \%$ fructose, $0.01 \%$ bile salt, $1 \%$ peptone 3 , and $0.2 \%$ Tween 20 , $\mathrm{wt} / \mathrm{vol}$ ) and the control (figure not shown). In the literature, these treatments had already been proposed to enhance the growth and selectivity of $L$. bulgaricus (Elli et al., 2000; Jenkins and Courtney, 2003; Tidow et al., 2012); however, the colonies in our study appeared somewhat transparent and poorly visible, which might be an indication of weak cells. Further investigation revealed that supplementing an RCM with a combination of $\mathrm{CaCl}_{2}$, uracil, and Tween $80(\mathrm{mRCM})$ produced larger and clearer colonies of $L$. bulgaricus $\mathrm{RR}$ than those grown on MRS and RCM (figures not shown). Based on these results, $\mathrm{CaCl}_{2}$, uracil, and Tween 80 were proposed as optimal components for the new medium. To evaluate the performance of $\mathrm{mRCM}, 2$ strains of L. bulgaricus (ATCC 11842 and RR) were grown and monitored in MRS, RCM, and mRCM for $12 \mathrm{~h}$ at $42^{\circ} \mathrm{C}$. The OD readings were recorded at $610 \mathrm{~nm}$ at 6 - $\mathrm{h}$ intervals (Tables 2 and 3 ).

Reinforced clostridial medium supplemented with $\mathrm{CaCl}_{2}$, uracil, and Tween 80 (mRCM) significantly enhanced the growth of both strains of L. bulgaricus $(P$

Table 3. Growth (mean $\pm \mathrm{SD} ; \mathrm{n}=3$; optical density at $610 \mathrm{~nm}$ ) of Lactobacillus bulgaricus $\mathrm{RR}$ in different media after $12 \mathrm{~h}$ of incubation at $42^{\circ} \mathrm{C}$

\begin{tabular}{lccc}
\hline & \multicolumn{3}{c}{ Time $(\mathrm{h})$} \\
\cline { 2 - 4 } Medium & 0 & 6 & 12 \\
\hline MRS & $0.001 \pm 0.00^{\mathrm{a}}$ & $0.07 \pm 0.15^{\mathrm{a}}$ & $0.96 \pm 0.16^{\mathrm{b}}$ \\
RCM & $0.001 \pm 0.00^{\mathrm{a}}$ & $0.06 \pm 0.07^{\mathrm{a}}$ & $0.85 \pm 0.10^{\mathrm{b}}$ \\
mRCM & $0.001 \pm 0.00^{\mathrm{a}}$ & $0.05 \pm 0.18^{\mathrm{a}}$ & $1.43 \pm 0.15^{\mathrm{a}}$ \\
\hline
\end{tabular}

$\overline{\mathrm{a}, \mathrm{b}}$ Means with different superscripts within a column differ significantly $(P<0.05)$.

${ }^{1} \mathrm{MRS}=$ de Man, Rogosa, and Sharpe medium; RCM = reinforced clostridial medium; $\mathrm{mRCM}=$ modified reinforced clostridial medium . 
$<0.05)$ as measured by the strains' levels of turbidity after $12 \mathrm{~h}$ of incubation. The L. bulgaricus $\mathrm{RR}$ strain reached an OD of 1.43 and a bacterial population of $8.42 \mathrm{log} \mathrm{cfu} / \mathrm{g}$ after $12 \mathrm{~h}$ of incubation compared with MRS $(\mathrm{OD}=0.96 ;$ population $=7.66 \mathrm{log} \mathrm{cfu} / \mathrm{g})$ and $\mathrm{RCM}(\mathrm{OD}=0.85$; population $=7.60 \mathrm{log} \mathrm{cfu} / \mathrm{g})$. Similar results were obtained for the ATCC 11842 strain. The OD for $\mathrm{mRCM}$ reached 1.24 with a bacterial population of $8.4 \mathrm{log} \mathrm{cfu} / \mathrm{g}$ relative to MRS $(\mathrm{OD}=0.71$; population $=7.64 \log \mathrm{cfu} / \mathrm{g})$ and $\mathrm{RCM}(\mathrm{OD}=0.66$; population $=7.48 \log \mathrm{cfu} / \mathrm{g}$; Tables 2 and 3; Figure 1). No significant growth differences for either strain of L. bulgaricus were observed between MRS and RCM. Interestingly, mRCM significantly inhibited the growth of all other LAB investigated in this study. Compared with MRS, mRCM showed 1.18, 1.65, and $0.91 \log \mathrm{cfu} / \mathrm{g}$ reductions in bacterial populations for Bifidobacterium, L. rhamnosus ATCC 53103, and L. reuteri 20016, respectively (Figure 2). These results would suggest an enhanced selectivity of mRCM for L. bulgaricus. The mechanism behind the inhibitory action of $\mathrm{mRCM}$ on other LAB was not investigated in the present study.

Figure 3 shows colonies of L. bulgaricus and ATCC 11842 on MRS, RCM, and mRCM supplemented with

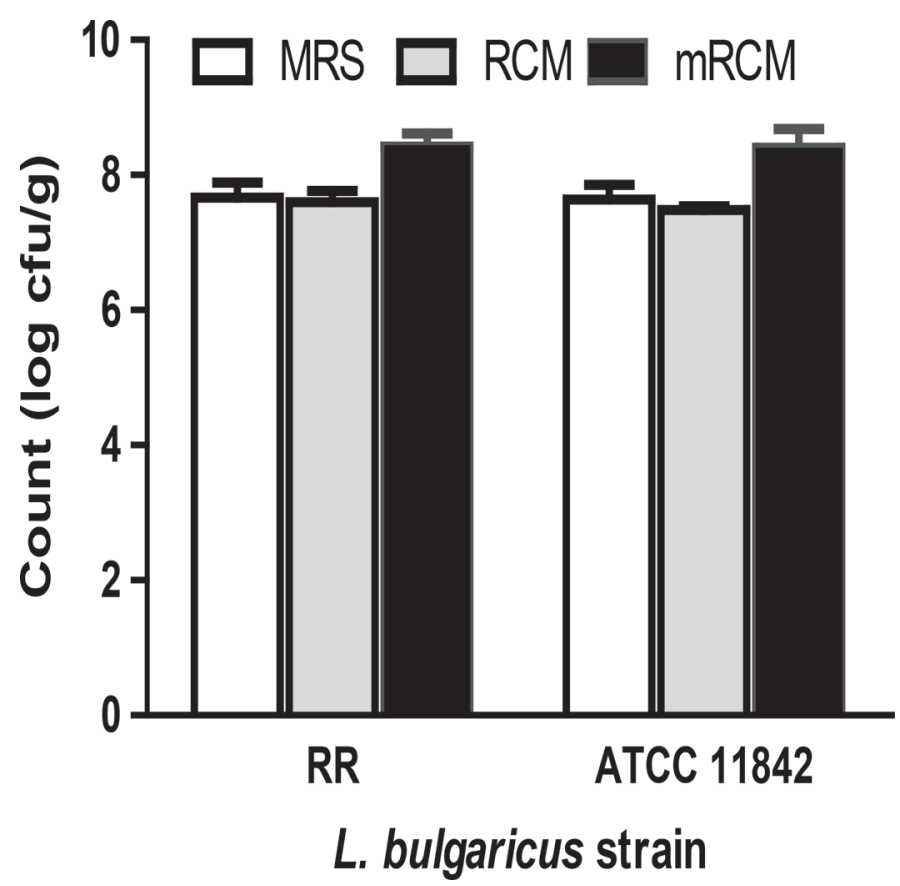

Figure 1. Bacterial populations (log cfu/g) of Lactobacillus bulgaricus $\mathrm{RR}$ and L. bulgaricus ATCC 11842 after $72 \mathrm{~h}$ of incubation at $42^{\circ} \mathrm{C}$ in de Man, Rogosa, and Sharpe medium (MRS); reinforced clostridial medium (RCM); and modified reinforced clostridial medium (mRCM). Error bars indicate SD for a representative experiment performed in triplicate.

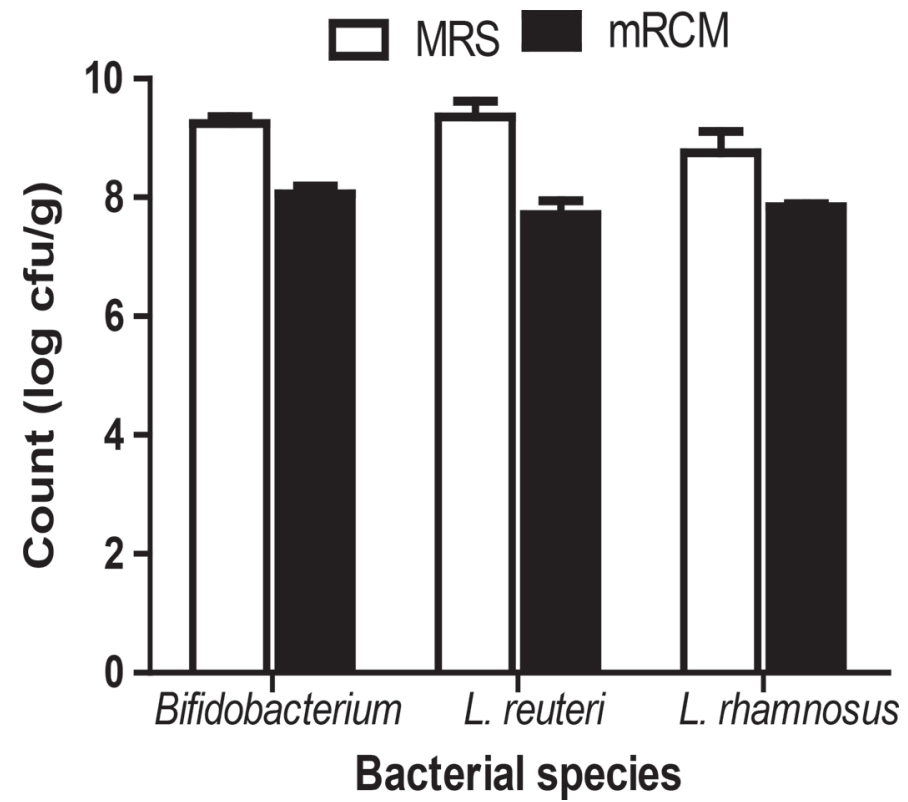

Figure 2. Bacterial populations of Lactobacillus reuteri 20016 Lactobacillus rhamnosus, and Bifidobacterium after $72 \mathrm{~h}$ of incubation at $42^{\circ} \mathrm{C}$ in de Man, Rogosa, and Sharpe medium (MRS) and modified reinforced clostridial medium (mRCM). Error bars indicate SD for a representative experiment performed in triplicate.

various dyes (aniline blue, bromocresol green, bromophenol blue, and X-gal). Colonies were observed for differences in structure, size, and appearance.

The addition of aniline blue dye to $\mathrm{mRCM}$ agar produced the most distinct and largest colonies of both L. bulgaricus RR and ATCC 11842 strains compared with the other differential ingredients (bromophenol blue, bromocresol green, and X-gal). Both strains of L. bulgaricus were large, irregularly shaped, and easily distinguishable with a darker blue center. We observed that the other differential ingredients produced smaller colonies of one or both strains of the bacteria. Although the addition of $\mathrm{X}$-gal to $\mathrm{mRCM}$ produced very distinct turquoise colonies of $L$. bulgaricus strains, the colony sizes of the bacteria were markedly diminished even at concentrations lower than those proposed by Galat et al. (2016; Figure 3). The RCM and MRS agars produced similar colonies of $L$. bulgaricus; however, colonies on MRS appeared to be paler and more transparent. Conversely, colonies of other LAB (Bifidobacterium, $L$. reuteri 20016, and L. rhamnosus ATCC 53103) on MRS appeared larger and very visible against mRCM-blue (Figure 4). Consequently, the addition of aniline blue dye to $\mathrm{mRCM}$ produced very distinct blue colonies of L. bulgaricus, which we were able to unambiguously differentiate. This result agrees with the assertion made by Kulp and Rettger (1924) that L. bulgaricus stained well with all basic aniline dyes. 
The second objective of this study was to validate mRCM with standard MRS and LA media. This test was done to determine the effectiveness of $\mathrm{mRCM}$ in differentiating $L$. bulgaricus in a mixed LAB culture. In the literature, many culture-based media for the evaluation of LAB have been reported; however, most of these methods have been evaluated only on isolated cultures even though it is necessary to validate medium performance in a mixed culture (Galat et al., 2016). Figure 5 shows the differential enumeration of $L$. bulgaricus RR and ATCC 11842 strains in a standard mixed LAB culture.

Analyses of standard mixed LAB culture and 7 commercial yogurt samples (Figures 5 and 6) validated the effectiveness of $\mathrm{mRCM}$ in the rapid enumeration and isolation of L. bulgaricus from other LAB species.

\begin{tabular}{|c|c|c|c|}
\hline Medium & Colony morpl & lology of L. bulgaricus & Colony description \\
\hline $\mathrm{RCM}$ & $\mathbf{R R}$ & $\begin{array}{c}\text { ATCC } 11842 \\
\cdots \\
\cdots\end{array}$ & $\begin{array}{l}\text { RR: } 3-5 \mathrm{~mm} \text { in diameter, whitish, flat and } \\
\text { irregular shaped, rough surface colonies. } \\
\text { ATCC } 11842: 2-4 \mathrm{~mm} \text { in diameter whitish, flat, } \\
\text { irregular shaped, smooth surface, shiny, slightly } \\
\text { elevated colonies. }\end{array}$ \\
\hline $\begin{array}{l}\mathrm{mRCM}- \\
\text { Aniline blue }\end{array}$ & & $0_{0}$ & $\begin{array}{l}\text { RR: } 3-8 \mathrm{~mm} \text { in diameter, light blue edges and } \\
\text { dark blue core, flat, irregular shaped, rough } \\
\text { surface colonies. } \\
\text { ATTC } 11842: 2-7 \mathrm{~mm} \text { in diameter, blue } \\
\text { colonies with darker blue dot-like center, } \\
\text { irregular shaped, smooth, slightly elevated. }\end{array}$ \\
\hline $\begin{array}{l}\text { mRCM- } \\
\text { Bromocresol } \\
\text { green }\end{array}$ & $\operatorname{sic}^{\circ}$ & $\because \quad \therefore$ & $\begin{array}{l}\text { RR: } 3-6 \mathrm{~mm} \text { in diameter, green, flat, irregular } \\
\text { shaped, rough surface colonies. } \\
\text { ATTC 11842: } 1-3 \mathrm{~mm} \text { in diameter, light green } \\
\text { edges with darker green dot-like center, irregular } \\
\text { shaped, smooth, shiny, slightly elevated. }\end{array}$ \\
\hline $\begin{array}{l}\text { mRCM- } \\
\text { Bromophenol } \\
\text { blue }\end{array}$ & & $\therefore:$ & $\begin{array}{l}\text { RR: } 2-4 \mathrm{~mm} \text { in diameter, blue, flat, irregular } \\
\text { shaped, rough surface colonies. } \\
\text { ATTC } 11842: 1-4 \mathrm{~mm} \text { in diameter, light blue } \\
\text { edges with darker blue dot-like center, irregular } \\
\text { shaped, smooth surface, shiny, slightly elevated. }\end{array}$ \\
\hline MRS & & 8 & $\begin{array}{l}\text { RR: 3-7 mm in diameter, creamy, transparent, } \\
\text { flat and irregular shaped, rough surface, } \\
\text { colonies. } \\
\text { ATCC } 11842: 3-6 \mathrm{~mm} \text { in diameter whitish, flat, } \\
\text { roundish, smooth surface, shiny, slightly } \\
\text { elevated colonies. }\end{array}$ \\
\hline $\mathrm{X}$-gal & & & $\begin{array}{l}\text { RR: } 1-2 \mathrm{~mm} \text { in diameter, turquoise, flat, } \\
\text { irregular shaped, rough surface colonies. } \\
\text { ATCC } 11842: 1-3 \mathrm{~mm} \text { in diameter turquoise, } \\
\text { flat, irregular shaped, smooth, shiny surface, } \\
\text { slightly elevated colonies. }\end{array}$ \\
\hline
\end{tabular}

Figure 3. Morphological structure of Lactobacillus bulgaricus RR and ATCC 11842 colonies on reinforced clostridial medium (RCM); modified reinforced clostridial medium (mRCM); and de Man, Rogosa, and Sharpe medium (MRS) supplemented with various dyes and X-gal. 


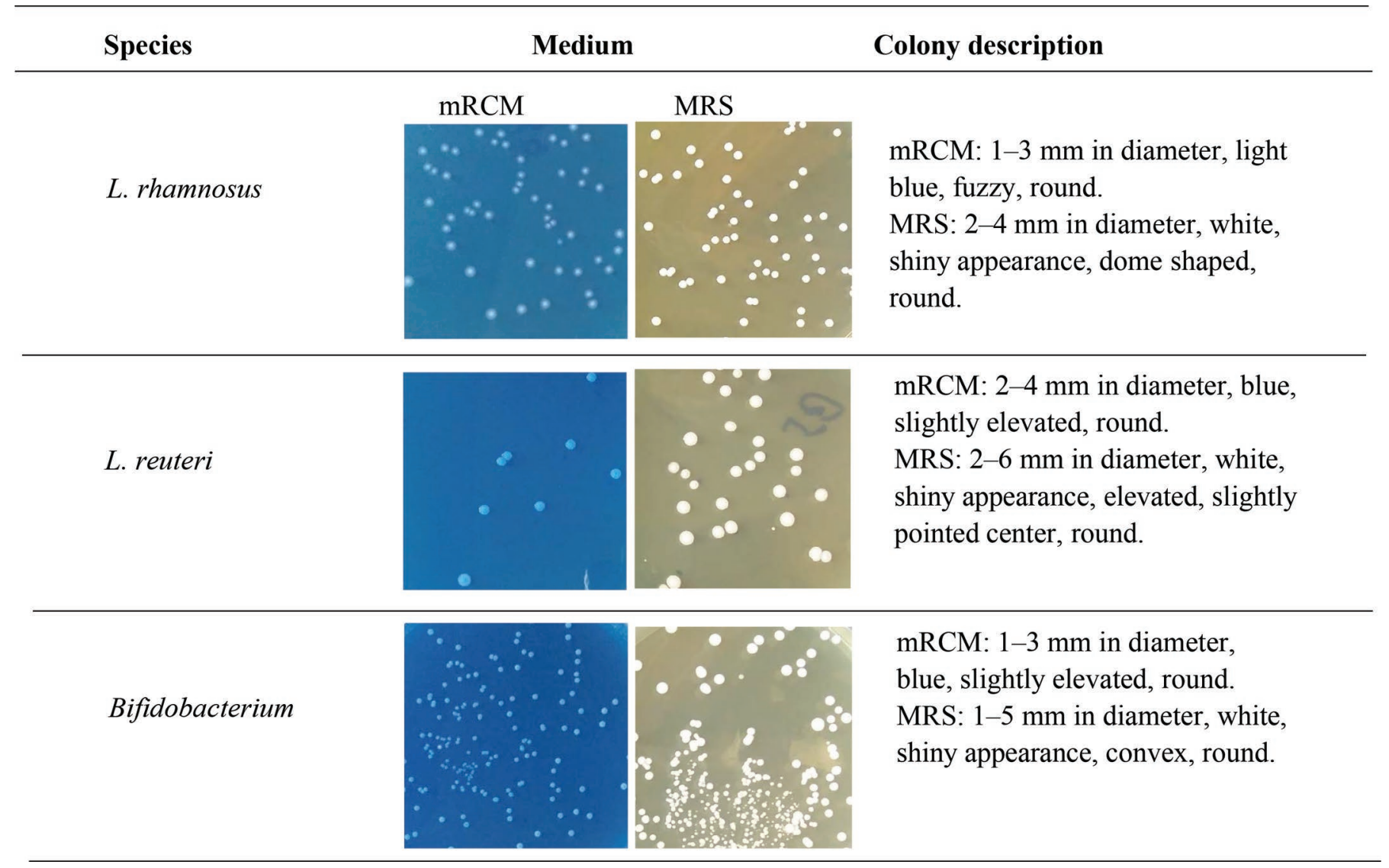

Figure 4. Morphological structure of Lactobacillus rhamnosus, Lactobacillus reuteri 20016, and Bifidobacterium colonies on modified reinforced clostridial medium (mRCM) and de Man, Rogosa, and Sharpe medium (MRS).

There were no significant differences in the bacterial counts among the 3 media (mRCM, MRS, and LA) tested (Table 4). However, colonies of L. bulgaricus that appeared on mRCM were clearer and much easier to differentiate from other LAB compared with those pro- duced on MRS and LA, as shown in Figure 6. Colonies of $L$. bulgaricus were distinct after $48 \mathrm{~h}$ of incubation, whereas those on MRS and LA appeared more visible only after $72 \mathrm{~h}$. Colonies of other LAB were larger on MRS compared with mRCM and LA, which would be

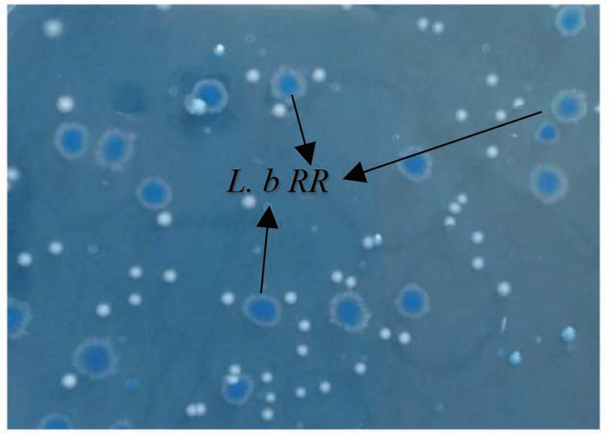

mRCM aniline blue

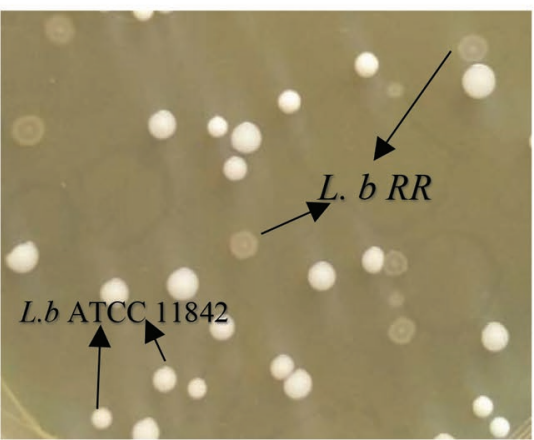

MRS

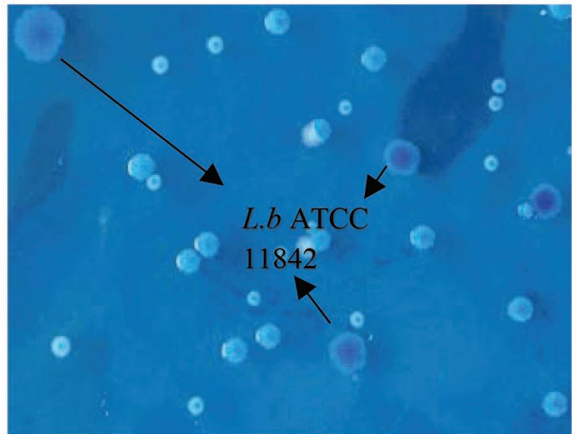

mRCM aniline blue

Figure 5. Selective enumeration of Lactobacillus bulgaricus RR and ATCC 11842 in standard mixed lactic acid bacteria culture on modified reinforced clostridial medium (mRCM) aniline blue and de Man, Rogosa, and Sharpe (MRS) agar. 


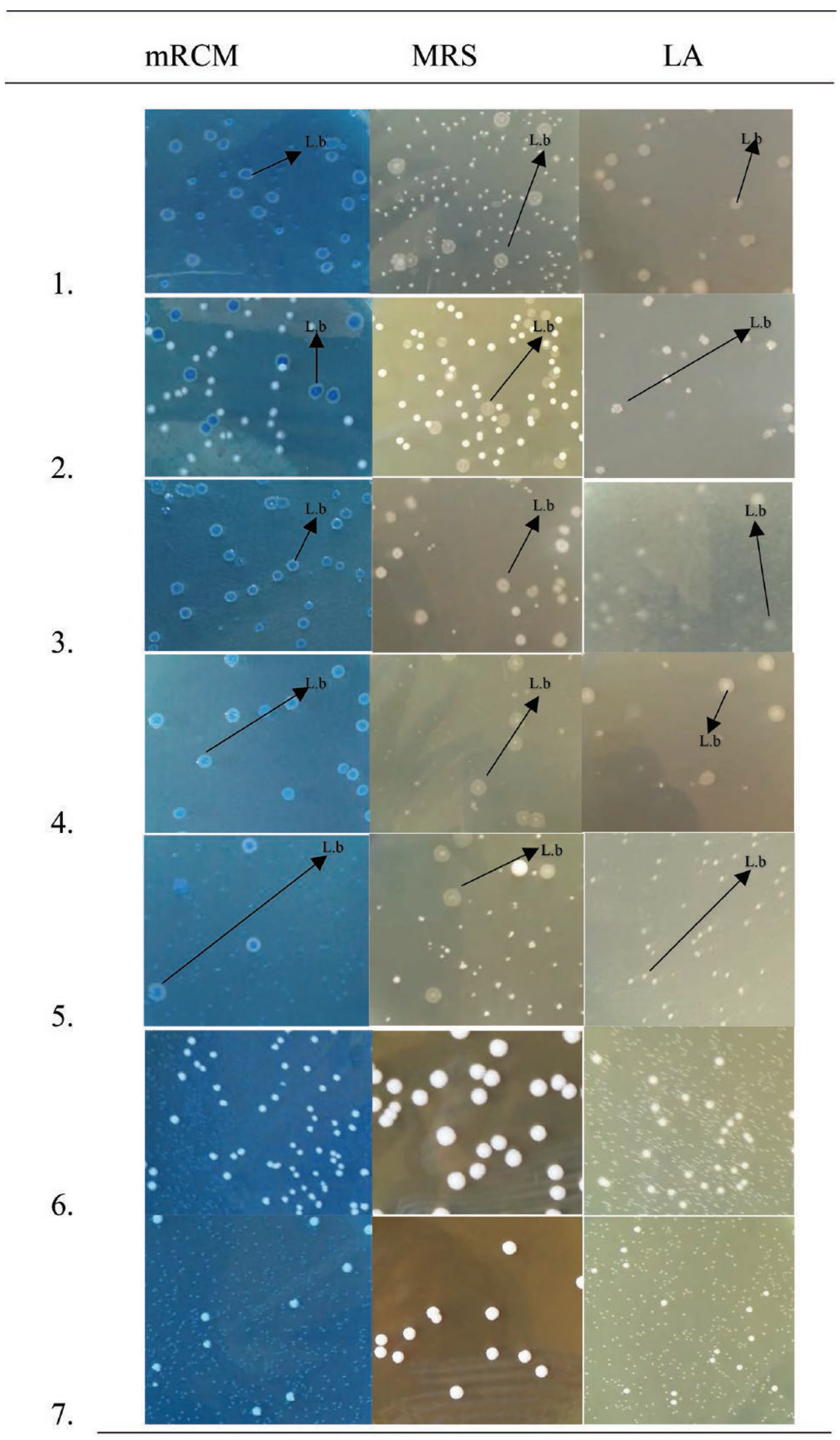

1. AYG, 2. GVO, 3. NSY, 4. HYG, 5. DND, 6. SFO, 7. OPO.

Figure 6. Selective enumeration of Lactobacillus bulgaricus from commercial yogurt samples on modified reinforced clostridial medium (mRCM) aniline blue; de Man, Rogosa, and Sharpe medium (MRS); and lactic agar (LA). See Table 1 for product code definitions. 
Table 4. Enumeration (mean $\pm \mathrm{SD} ; \mathrm{n}=3$ ) of Lactobacillus bulgaricus (log cfu/g) from 7 yogurt products on de Man, Rogosa, and Sharpe medium (MRS); modified reinforced clostridial medium (mRCM); and lactic agar (LA) after $72 \mathrm{~h}$ of incubation at $42^{\circ} \mathrm{C}$

\begin{tabular}{lccc}
\hline $\begin{array}{l}\text { Product }_{\text {code }^{1}} \\
\text { NSY }\end{array}$ & MRS & mRCM & LA \\
\hline AYG & $7.82 \pm 0.10^{\mathrm{a}}$ & $6.79 \pm 0.19^{\mathrm{a}}$ & $6.70 \pm 0.05^{\mathrm{a}}$ \\
HYG & $7.73 \pm 0.07^{\mathrm{a}}$ & $7.58 \pm 0.02^{\mathrm{a}}$ & $7.20 \pm 0.59^{\mathrm{a}}$ \\
GVO & $7.41 \pm 0.39^{\mathrm{a}}$ & $7.91 \pm 0.41^{\mathrm{a}}$ & $7.60 \pm 0.15^{\mathrm{a}}$ \\
OPO & $\mathrm{ND}^{2}$ & $\mathrm{ND}$ & $7.59 \pm 0.27^{\mathrm{a}}$ \\
SFO & $\mathrm{ND}_{\mathrm{ND}}$ & $\mathrm{ND}$ & $\mathrm{ND}$ \\
DN & $5.52 \pm 0.13^{\mathrm{a}}$ & $5.52 \pm 0.14^{\mathrm{a}}$ & $5.42 \pm 0.06^{\mathrm{a}}$ \\
\hline
\end{tabular}

${ }^{\mathrm{a}}$ Means with the same superscript within a column are not significantly different $(P>0.05)$.

${ }^{1}$ See Table 1 for product descriptions.

${ }^{2}$ Not detected.

an indication that $\mathrm{mRCM}$ significantly suppresses the growth of all LAB except for L. bulgaricus. Two of the 4 yogurt samples (samples SFO and OPO) purchased from a local store in Greensboro, North Carolina, did not contain L. bulgaricus strains even though the product labels indicated otherwise. However, all 3 yogurt samples purchased in the Middle East contained $L$. bulgaricus strains. This result further emphasizes the need for the isolation of more L. bulgaricus strains from natural sources in order to meet market demand in the United States.

\section{DISCUSSION}

In this study, we developed mRCM, a selective medium based on the specific nutritional requirements of L. bulgaricus. Lactobacillus delbrueckii ssp. bulgaricus is considered one of the most important LAB due to its health benefits and its role in several industrial applications (Gouesbet et al., 2002). We studied 2 strains of L. bulgaricus - RR and ATCC 11842. Lactobacillus bulgaricus $\mathrm{RR}$ is a particularly important strain used in yogurt production because this strain produces exopolysaccharides that are responsible for the textural quality and mouth-feel of yogurt. Study treatments were selected based on the general metabolic needs of LAB and were tested on the L. bulgaricus RR strain in order to determine the specific needs of the bacteria. Following a preliminary assessment, we discovered that calcium chloride, Tween 80, and uracil significantly enhanced the colony size and visibility of $L$. bulgaricus RR. This result was expected because Tidow et al. (2012) demonstrated that calcium chloride functions as a cell regulator or cell signal messenger. This feature makes calcium chloride essential for the enhanced growth of $L$. bulgaricus, as elimination of iron and manganese from the medium will not affect the growth of $L$. bulgaricus provided calcium is present (Chervaux et al., 2000). Uracil was reported to be the most essential source of pyrimidine for lactobacilli because adenine and guanine are readily synthesized from inosine by lactobacilli (Elli et al., 2000). Uracil facilitates RNA synthesis and cell division in lactobacilli (Elli et al., 2002), whereas Tween 80 acts as a nonionic surfactant, enhancing the absorption of nutrients by microorganisms (Jenkins and Courtney, 2003). Aniline blue dye was the only differential ingredient that did not inhibit the colony size of L. bulgaricus RR and ATCC 11842. However, a slight to significant reduction in colony size was observed when bromocresol green (Yamani and Ibrahim, 1996), bromophenol blue (Lee and Lee, 2008), dyes and X-gal (Galat et al., 2016) were used as differential ingredients. Many media such as Elliker's LA (Elliker et al., 1956), MRS (de Man et al., 1960), Lee's agar (Lee et al., 1974), bromocresol green whey agar (Yamani and Ibrahim, 1996), RCA 5.3 and MRS 5.2 (Shah, 2000), and MRS-fructose (Tabasco et al., 2007) have been proposed for the enumeration and differentiation of $L$. bulgaricus. Most of these media have not been able to selectively promote the growth of $L$. bulgaricus while actively inhibiting the growth of other LAB. However, mRCM-blue was successful in selectively enumerating and differentiating $L$. bulgaricus in yogurt products containing mixed lactic acid cultures.

We plan further exploration of this work in order to validate the efficacy of RCM-blue with a wide range of commercial yogurt products as well as with other dairy products that contain $L$. bulgaricus. In addition, we want to investigate the mechanism of inhibitory action of the proposed medium against other LAB species.

\section{CONCLUSIONS}

The results of the current study demonstrated that mRCM-blue (RCM supplemented with $\mathrm{CaCl}_{2}$, uracil, Tween 80, and aniline blue dye) is superior to MRS, LA, and RCM with regard to the enumeration and differentiation of $L$. bulgaricus in mixed LAB cultures. Modified RCM-blue can thus be used industrially to rapidly grow and isolate $L$. bulgaricus strains from natural sources in order to meet the high industry demand for these bacteria and can also be used microbiologically for the analyses of new strains of $L$. bulgaricus.

\section{ACKNOWLEDGMENTS}

This work was supported, in part, by the Agriculture Research Station and the Department of Family and Consumer Sciences at North Carolina Agriculture and Technical State University (Greensboro) through the 
USDA Evans-Allen Program (project no. NC.X-291-515-170-1).

\section{REFERENCES}

Anukam, K. C., and G. Reid. 2007. Probiotics: 100 years (1907-2007) after Elie Metchnikoff's observation. Comm. Curr. Res. Edu. Topics Trends Appl. Microbiol. 1:466-474.

Borruel, N., M. Carol, F. Casellas, M. Antolin, F. De Lara, E. Espin, J. Naval, F. Guarner, and J. R. Malagelada. 2002. Increased mucosal tumor necrosis factor $\alpha$ production in Crohn's disease can be downregulated ex vivo by probiotic bacteria. Gut 51:659-664.

Chervaux, C., S. D. Ehrlich, and E. Maguin. 2000. Physiological study of Lactobacillus delbrueckii ssp. bulgaricus strains in a novel chemically defined medium. Appl. Environ. Microbiol. 66:5306-5311. https://doi.org/10.1128/AEM.66.12.5306-5311.2000.

de Man, J. C., D. Rogosa, and M. E. Sharpe. 1960. A medium for the cultivation of lactobacilli. J. Appl. Microbiol. 23:130-135. https:// doi.org/10.1111/j.1365-2672.1960.tb00188.x.

Elli, M., R. Zink, B. Marchesini-Huber, and R. Reniero. 2002. Synthetic medium for cultivating lactobacilli and bifidobacteria. U.S. patent no. 6,340,585. U.S. Patent and Trademark Office, Washington, DC.

Elli, M., R. Zink, A. Rytz, R. Reniero, and L. Morelli. 2000. Iron requirement of Lactobacillus spp. in completely chemically defined growth media. J. Appl. Microbiol. 88:695-703.

Elliker, P. R., A. W. Anderson, and G. Hannesson. 1956. An agar culture medium for lactic acid streptococci and lactobacilli. J. Dairy Sci. 39:1611-1612.

Galat, A., J. Dufresne, J. Combrisson, J. Thépaut, L. BoumgharBourtchai, M. Boyer, and C. Fourmestraux. 2016. Novel method based on chromogenic media for discrimination and selective enumeration of lactic acid bacteria in fermented milk products. Food Microbiol. 55:86-94. https://doi.org/10.1016/j.fm.2015.11.005.

Gouesbet, G., G. Jan, and P. Boyaval. 2002. Two-dimensional electrophoresis study of Lactobacillus delbrueckii ssp. bulgaricus thermotolerance. Appl. Environ. Microbiol. 68:1055-1063. https://doi .org/10.1128/AEM.68.3.1055-1063.2002.

Jenkins, J. K., and P. D. Courtney. 2003. Lactobacillus growth and membrane composition in the presence of linoleic or conjugated linoleic acid. Can. J. Microbiol. 49:51-57. https://doi.org/10.1139/ w03-003.

Kulp, W. L., and L. F. Rettger. 1924. Comparative study of Lactobacillus acidophilus and Lactobacillus bulgaricus. J. Bacteriol. 9:357-395.
Lee, H. M., and Y. Lee. 2008. A differential medium for lactic acid-producing bacteria in a mixed culture. Lett. Appl. Microbiol. 46:676-681. https://doi.org/10.1111/j.1472-765X.2008.02371.x.

Lee, S. Y., E. R. Vedamuthu, C. J. Washam, and G. W. Reinbold. 1974. An agar medium for the differential enumeration of yogurt starter bacteria. J. Milk and Food Tech. 37:272-276. https://doi .org/10.4315/0022-2747-37.5.272

Makino, S., S. Ikegami, A. Kume, H. Horiuchi, H. Sasaki, and N. Orii. 2010. Reducing the risk of infection in the elderly by dietary intake of yogurt fermented with Lactobacillus delbrueckii ssp. bulgaricus OLL1073R-1. Br. J. Nutr. 104:998-1006. https://doi.org/10.1017/ S000711451000173X

Matalon, M. E., and W. E. Sandine. 1986. Improved media for differentiation of rods and cocci in yogurt. J. Dairy Sci. 69:2569-2576.

Michaylova, M., M. Svetlana, K. Kimura, S. Takashi, and K. Isawa. 2007. Isolation and characterisation of Lactobacillus delbrueckii ssp. bulgaricus and Streptococcus thermophilus form plants in Bulgaria. FEMS Microbiol. Lett. 269:160-169.

Nielsen, S. J., and C. Ogden. 2015. Trends in yogurt consumption, US adults, 1999-2012. FASEB J. 29(Suppl.):587.17. (Abstr.)

Shah, N. P. 2000. Probiotic bacteria: Selective enumeration and survival in dairy foods. J. Dairy Sci. 83:894-907. https://doi.org/10 .3168/jds.S0022-0302(00)74953-8.

Tabasco, R., T. Paarup, C. Janer, C. Peláez, and T. Requena. 2007. Selective enumeration and identification of mixed cultures of Streptococcus thermophilus, Lactobacillus delbrueckii ssp. bulgaricus, L. acidophilus, L. paracasei ssp. paracasei and Bifidobacterium lactis in fermented milk. Int. Dairy J. 17:1107-1114. https://doi .org/10.1016/j.idairyj.2007.01.010.

Tidow, H., L. R. Poulsen, A. Andreeva, M. Knudsen, K. L. Hein, C. Wiuf, M. G. Palmgren, and P. Nissen. 2012. A bimodular mechanism of calcium control in eukaryotes. Nature 491:468-472. https://doi.org/10.1038/nature11539.

Van de Casteele, S., T. Vanheuverzwijn, T. Ruyssen, P. Van Assche, J. Swings, and G. Huys. 2006. Evaluation of culture media for selective enumeration of probiotic strains of lactobacilli and bifidobacteria in combination with yogurt or cheese starters. Int. Dairy J. 16:1470-1476. https://doi.org/10.1016/j.idairyj.2005.12.002.

Wollowski, I., S. T. Ji, A. T. Bakalinsky, C. Neudecker, and B. L. PoolZobel. 1999. Bacteria used for the production of yogurt inactivate carcinogens and prevent DNA damage in the colon of rats. J. Nutr. 129:77-82.

Yamani, M. I., and S. A. Ibrahim. 1996. The differential enumeration of Lactobacillus delbrueckii subspecies bulgaricus and Streptococcus salivarius subspecies thermophilus in yogurt and labneh using an improved whey medium. Int. J. Dairy Tech. 49:103-108. https:// doi.org/10.1111/j.1471-0307.1996.tb02500.x. 